\title{
OPTIMASI JARINGAN DENGAN SPANNING TREE UNTUK CONGESTION MANAGEMENT
}

\author{
Mayliana \\ Computer Science Department, School of Computer Science, Binus University \\ Jl. K.H. Syahdan No. 9, Palmerah, Jakarta Barat 11480 \\ mayliana@binus.edu
}

\begin{abstract}
A proper network optimization is needed to deal with problems on the network and to minimize latency in the data flow in a dense network. The data stream is directed into the right channels so that the optimal network speed and latency can be minimized. Spanning tree is one of the algorithms that can be used. The purpose of the Spanning tree is to prevent and reduce the loops in the network by negotiating free path and as well as to increase network uptime through redundancy (back-up). To comprehend spanning tree, the first important thing to know is how bridges and switches perform their functions. The more switches used, the use of the spanning tree becomes more important. With the spanning tree protocol, a broadcast storm can be prevented that can achieved network optimization.
\end{abstract}

Keywords: network optimization, spanning tree, congestion management

\begin{abstract}
ABSTRAK
Optimasi jaringan yang baik diperlukan untuk menangani masalah pada jaringan dan meminimumkan latency pada aliran data yang padat di jaringan. Aliran data diarahkan ke jalur-jalur yang benar agar kecepatan jaringan menjadi optimal dan latency bisa diperkecil. Spanning tree adalah salah satu algoritma yang bisa digunakan. Tujuan Spanning tree adalah mencegah dan mengurangi loop di jaringan dengan menegosiasikan jalur yang bebas dan meningkatkan network uptime melalui redundancy (back up). Untuk memahami spanning tree, hal pertama yang penting adalah mengetahui bagaimana bridge dan switch melakukan fungsinya. Semakin banyak switch yang dipakai, penggunaan spanning tree menjadi semakin penting. Dengan Spanning tree Protocol, broadcast storm dapat dicegah sehingga optimasi jaringan menjadi tercapai.
\end{abstract}

Kata kunci: network optimization, spanning tree, congestion management 


\section{PENDAHULUAN}

Jaringan merupakan salah satu teknologi yang tumbuh secara eksponensial dalam kurun waktu 20 tahun terakhir (Atif, 2011). Teknologi jaringan mengalami perubahan yang begitu cepat untuk memenuhi peningkatan pesat dari kebutuhan dasar seperti berbagi data dan printer, atau kebutuhan lain yang lebih tinggi seperti video conferencing. Tantangannya adalah bagaimana menghubungkan jaringan-jaringan yang saling terkait tersebut sehingga semua pengguna dapat menggunakan sumber daya yang ada di jaringan dan ketika harus membagi jaringan yang besar menjadi jaringan-jaringan yang lebih kecil karena performance jaringan yang lambat.

Sebuah jaringan yang besar cenderung melambat karena lalu lintas data yang terlalu padat sehingga terjadi apa yang disebut congestion (kemacetan). Network congestion dapat disebabkan oleh: (1) terlalu banyak host (alat-alat yang terhubung ke jaringan dan bisa menerima dan mengirim informasi dari alat-alat lain, misalkan printer, komputer, dan lain-lain) di dalam sebuah broadcast domain; (2) broadcast storm, yaitu kejadian yang tidak diinginkan dalam jaringan yang disebabkan oleh transmisi secara serentak dari sejumlah broadcast yang melalui segmen jaringan tersebut sehingga bisa membuat bandwith jaringan kewalahan, yang meyebabkan time out; (3) multicasting; (4) bandwith kecil, hal ini dapat dianalogikan dengan jalan yang sempit dan banyak mobil yang melalui jalan tersebut (Lammle, 2002).

Memisahkan collision domain dan broadcast domain adalah salah satu cara untuk mengurangi network congestion. Hal ini bisa dilakukan dengan menggunakan router, switch dan bridge. Algoritma yang dipakai untuk melakukan hal tersebut salah satunya adalah spanning tree, khususnya pada switch.

Fungsi Switch menurut Lammle (2002) antara lain: (1) mempelajari alamat - switch dan bridge mengingat alamat hardware host asal dari setiap frame yang diterimanya pada sebuah interface, dan keduanya memasukkan informasi ini ke sebuah database MAC yang disebut tabel forward/filter; (2) keputusan forward/filter - ketika sebuah frame diterima pada sebuah interface, switch akan melihat ke alamat hardware tujuan dan menemukan interface exit pada database MAC. Frame hanya di-forward keluar port tujuan yang ditentukan; (3) menghindari loop - jika dibuat banyak koneksi antar switch untuk tujuan redundancy, maka loop jaringan dapat terjadi. Spanning tree Proctocol akan digunakan untuk menghentikan loop-loop jaringan tetapi dengan tetap memperbolehkan redundancy.

\section{METODE}

\section{Perancangan}

Perancangan dimulai dengan membangun model jaringan di Packet Tracer sedemikian rupa sehingga memungkinkan sering terjadinya loop dan redundancy lalu menganalisa hasil Spanning tree dengan memasukkan parameter sebelum dan sesudah dilakukan Spanning tree.

Packet Tracer digunakan untuk membuat model jaringan dengan dua switch multilayer dan switch layer 2 dan cloud (Gambar 1). 


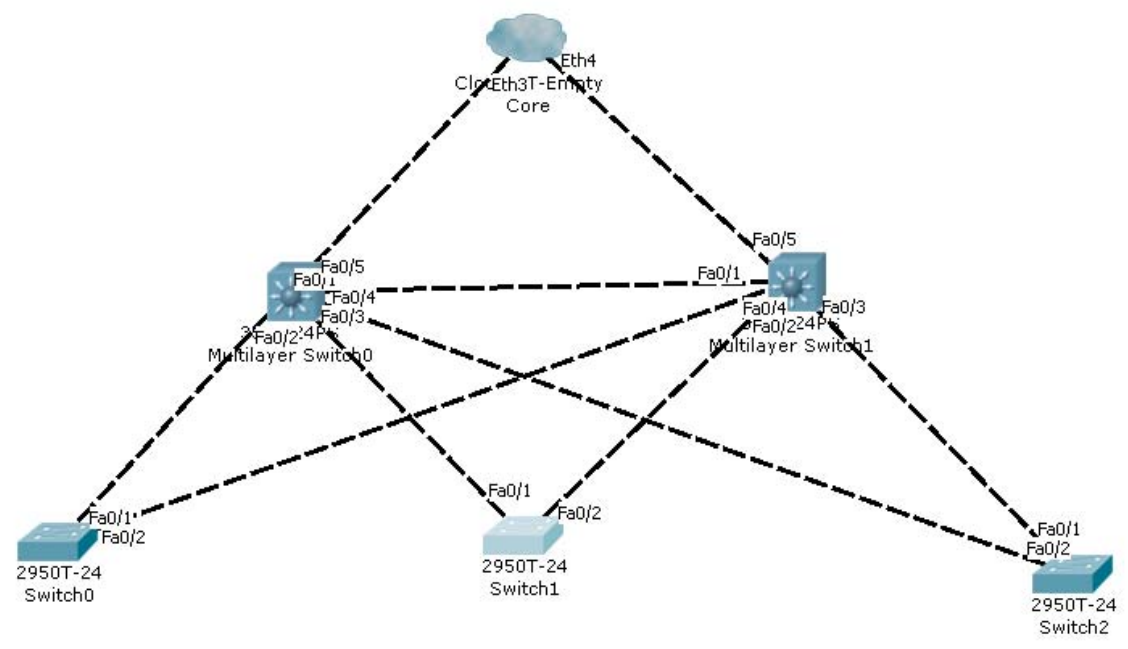

Gambar 1 Model jaringan yang akan di spanning tree

Keterangan:

\begin{tabular}{l|ccccc}
\hline \multirow{2}{*}{$\begin{array}{l}\text { MAC } \\
\text { Address } \\
\text { Priority }\end{array}$} & $\begin{array}{c}\text { MultiLayer } \\
\text { Switch 0 }\end{array}$ & $\begin{array}{c}\text { MultiLayer Switch } \\
\mathbf{1}\end{array}$ & Switch 0 & Switch 1 & Switch 2 \\
\cline { 2 - 6 } Port & 32769 & 0004.9A09.A539 & $0010.1164 .77 \mathrm{E} 1$ & $0005.5 \mathrm{EC} 2.380 \mathrm{D}$ & $0001.9605 . \mathrm{C} 006$ \\
& $\begin{array}{c}\mathrm{Fa} / 1, \mathrm{Fa} / 2, \mathrm{Fa} 0 / 3, \\
\mathrm{Fa} / 4, \mathrm{Fa} / 05\end{array}$ & $\begin{array}{c}\mathrm{Fa} 0 / 1, \mathrm{Fa} 0 / 2, \mathrm{Fa} 0 / 3, \mathrm{~F} \\
\mathrm{a} 0 / 4, \mathrm{Fa} / 05\end{array}$ & $\mathrm{Fa} 0 / 1, \mathrm{Fa} 0 / 2$ & $\mathrm{Fa} 0 / 1, \mathrm{Fa} 0 / 2$ & $\mathrm{Fa} 0 / 1, \mathrm{Fa} 0 / 2$ \\
\hline
\end{tabular}

\section{Tinjauan Kepustakaan}

\section{Optimasi Spanning tree}

Optimasi spanning tree dalam teori dapat dicapai dengan berbagai cara. Ketika Spanning tree pertama kali dikembangkan, bridge memforward BPDU (Bridge Protocol Data Unit) dan frame data dalam software, menghasilkan propagasi panjang dan delay dalam memproses BPDU. Karena alasan tersebut, perancangan spanning tree sangat tidak mau mengambil resiko dalam pemilihan nilai untuk parameter konvergen spanning tree. Kembali ketika protokol dikembangkan, mempertimbangkan kemampuan menerima untuk tujuan mencapai topologi reconvergence yang bagus. Algoritma pencarian node terdekat seperti The bounded diameter minimum spanning tree (BDMST) bisa diterapkan dalam perancangan jaringan untuk optimasi Spanning tree (Arora, 2013)

\section{Pemilihan Lokasi Root Bridge}

Parameter Max Age, Forward Delay dan Hello Time umum untuk semua switch dalam Spanning tree. Sehingga penting untuk menyetel parameter tersebut dan mensetnya pada root bridge dan backup root bridge. Parameter-parameter tersebut diatur pada root bridge dan dipropagasikan oleh BPDU untuk semua bridge lain dalam spanning tree. Meskipun penyetelan sederhana terhadap beberapa parameter mungkin akan mengoptimasi operasi spanning tree, pertimbangan penting lainnya adalah jarak dari root bridge. Semenjak root bridge bertanggung jawab untuk menghasilkan konfigurasi dan manajemen BPDU, penting untuk menempatkan root bridge pada lokasi optimum pada jaringan. Secara logika menyatakan bahwa root bridge harus berada pada pusat topologi, atau berjarak sama dari semua Spanning tree leaf nya. Sehingga menyebabkan topology change notifications and acknowledgment berkembang secara cepat pada network bridge. 


\section{Penyetelan Parameter Spanning Tree}

Perubahan parameter Spanning tree, ketika dihasilkan dalam penyimpangan singkat, mungkin tidak dapat ditebak dan mungkin menghasilkan kerugian. Menset Max Age turun ke nilai minimum 6 detik dapat berakibat BPDU dibuang terlalu awal. Selama operasi normal, root bridge secara berkala mengirim konfigurasi BPDU setiap hello time (default 2 detik). BPDU ini, dalam keadaan bergiliran, dipropagasikan ke bridge downstream dari root. Jika frame BPDU dengan tidak sengaja dibuang, nilai kecil untuk Max Age dapat menyebabkan bridge membuang konfigurasi sekarang dan menghitung kembali Spanning tree. Menyetel Forward Delay turun ke nilai minimum 4 detik berarti ketika mengalihkan dari Blocking ke Forwarding port akan menghabiskan waktu 4 detik untuk melihat state dan 4 detik untuk mempelajari state. Ini berarti hanya 8 detik dalam melihat dan mempelajari state dimana BPDU mengindikasikan loop harus diterima dan diproses. Dengan demikian menset nilai terlalu rendah mungkin tidak mempertanggung jawabkan fakta bahwa BPDU dapat tidak sengaja dihilangkan dan dapat berakibat loop dan mungkin sebuah broadcast storm.

\section{HASIL DAN PEMBAHASAN}

\section{Proses Spanning Tree}

Pertama-tama akan dilihat Switch dengan bridgeID terkecil dan didapatkan Switch 2 maka Switch 2 akan menjadi Root Bridge, lalu selanjutnya akan ditentukan Root Port yaitu yang memiliki cost terkecil ke Root Bridge yaitu Fa0/4 pada MultiLayer Switch 0 dan Fa0/3 pada Multi Layer Switch 1, lalu langkah selanjutnya menentukan Designated Port dan Undesignated Port. Kita anggap semuanya adalah Designated port, untuk menentukkan Undesignated portnya maka kita akan menggunakan aturan bahwa semua port yang menuju root bridge tidak boleh diblok maka semua port yang menuju root bridge adalah Designated port. Aturan kedua yaitu tidak boleh ada dua designated port dalam satu jalur. Yang menjadi Designated Portnya adalah portnya terkecil. Sehingga didapat Proses spanning tree seperti Gambar 2, di mana Show Spanning tree pada beberapa switch ditampilkan pada Gambar 3 - Gambar 7.

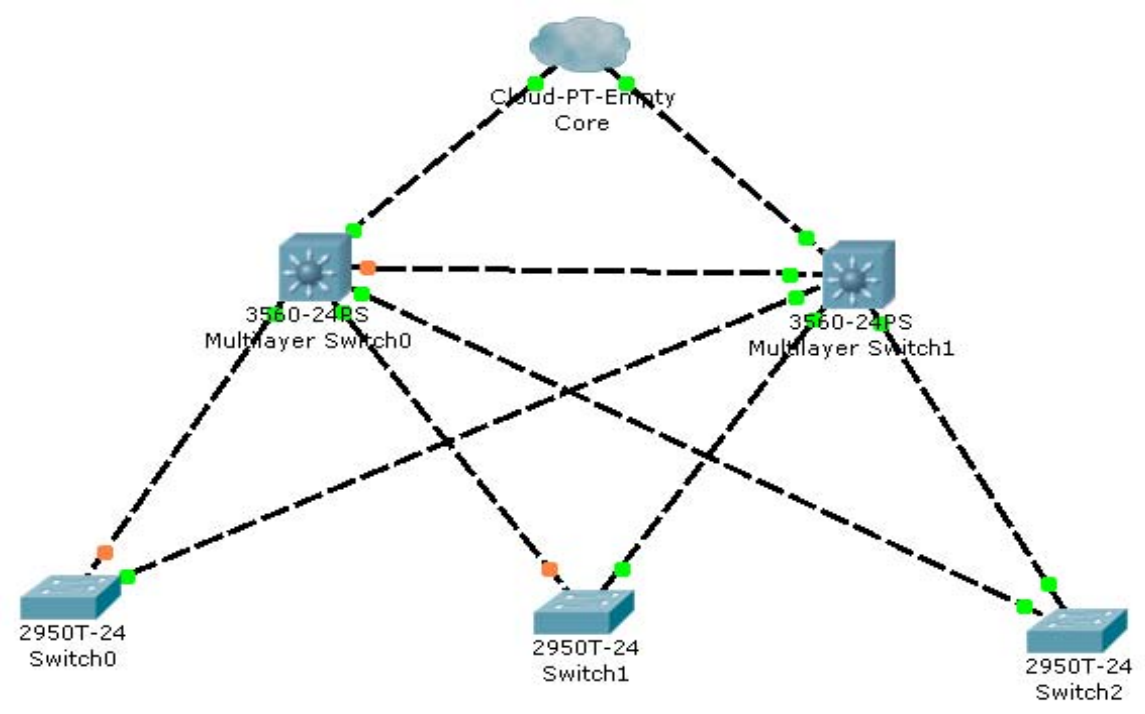

Gambar 2 Proses Spanning tree, hijau untuk designated port dan merah untuk undesignated port 


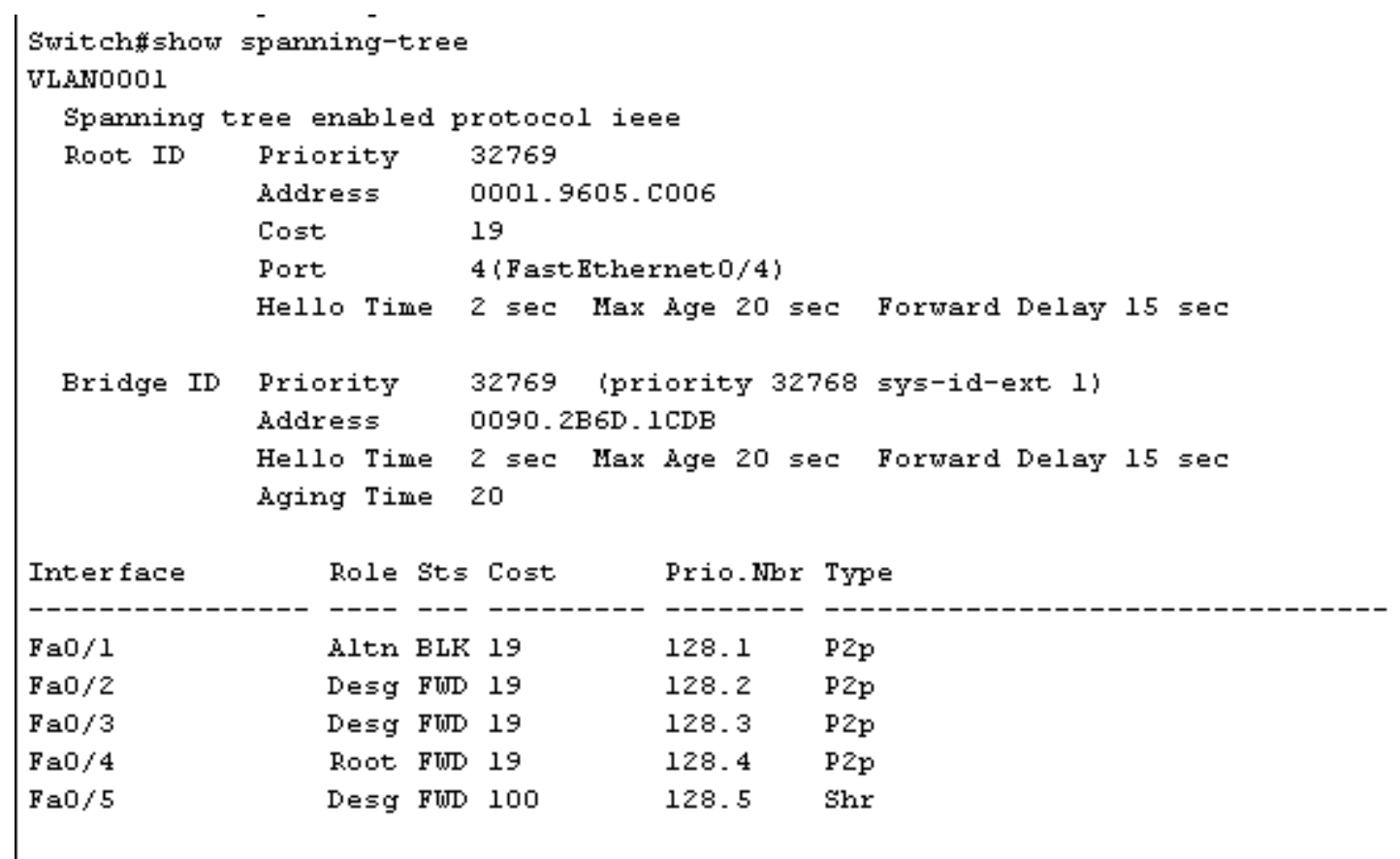

Gambar 3 Show Spanning tree Switch Multilayer 0

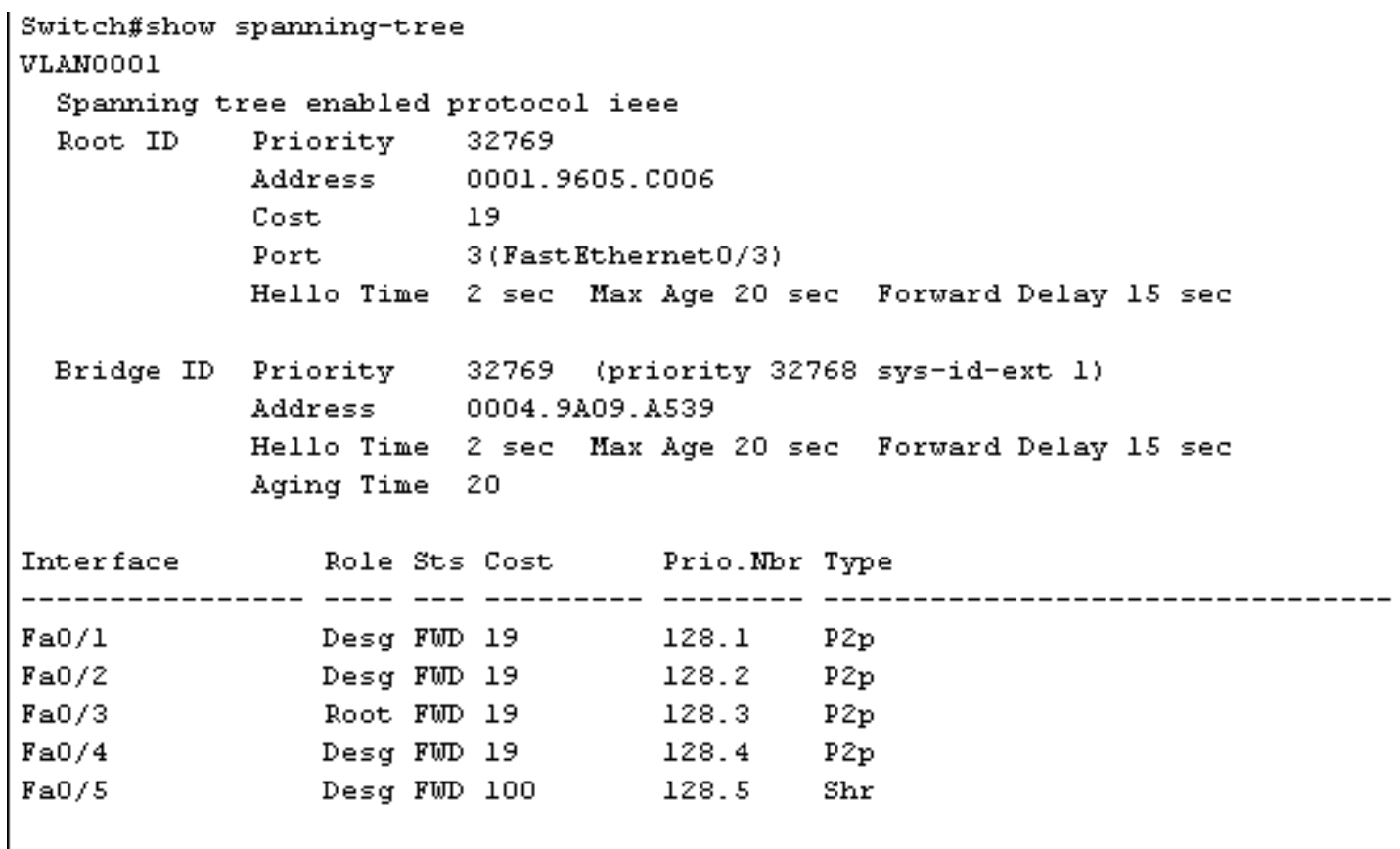

Gambar 4 Show Spanning tree Switch Multilayer 1 


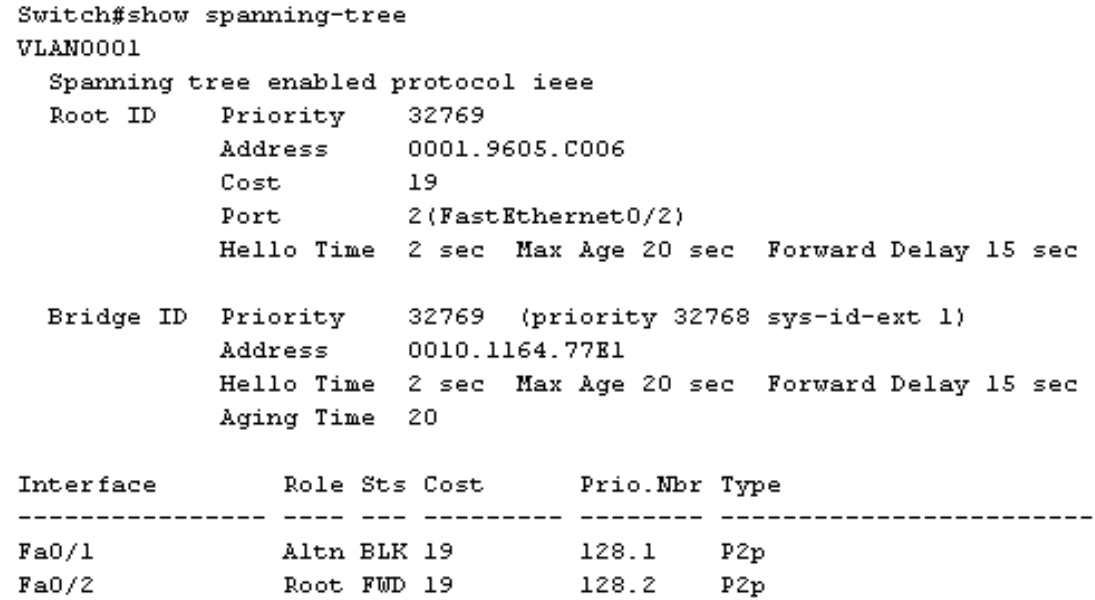

Gambar 5 Show Spanning tree Switch 0

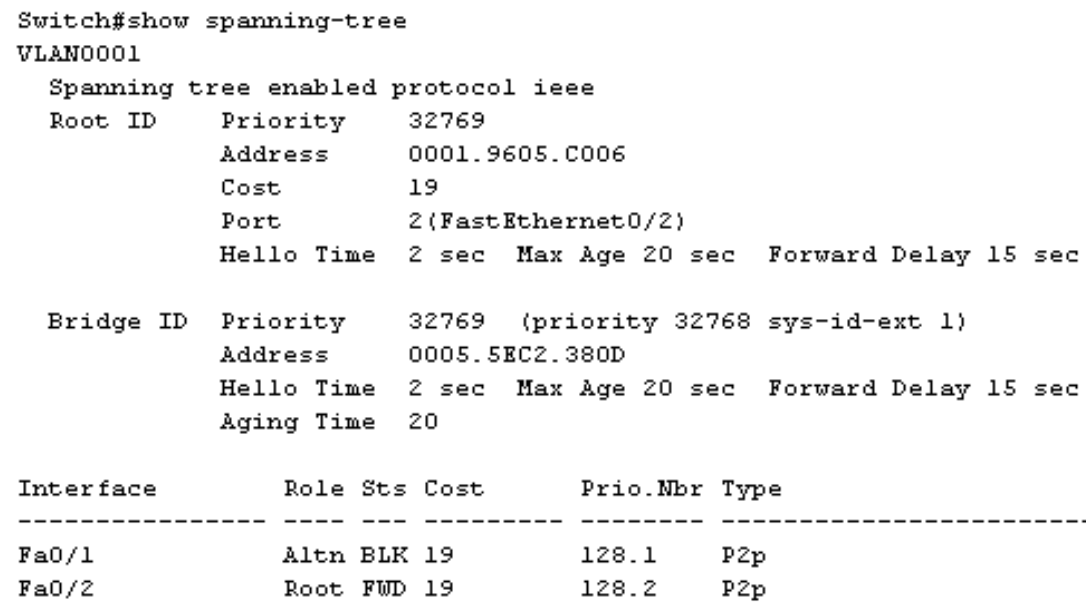

Gambar 6 Show Spanning tree Switch 1

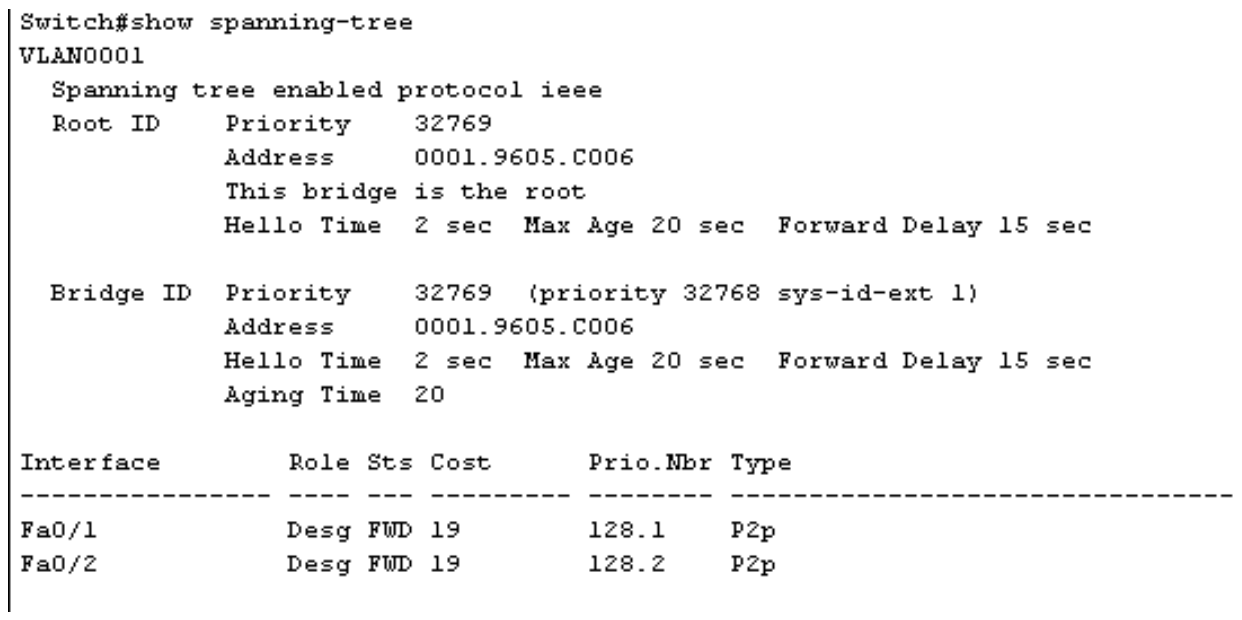

Gambar 7 Show Spanning tree Switch 2. 


\section{Nilai Parameter dan Pembahasan}

Nilai untuk parameter yang digunakan ditampilkan pada Tabel 1.

Tabel 1 Nilai Parameter

\begin{tabular}{llllll}
\hline Parameter & $\begin{array}{l}\text { MultiLayer } \\
\text { Switch 0 }\end{array}$ & $\begin{array}{l}\text { MultiLayer } \\
\text { Switch 1 }\end{array}$ & Switch 0 & Switch 1 & Switch 2 \\
\hline Hello Time & $2 \mathrm{sec}$ & $2 \mathrm{sec}$ & $2 \mathrm{sec}$ & $2 \mathrm{sec}$ & $2 \mathrm{sec}$ \\
Max Age & $20 \mathrm{sec}$ & $20 \mathrm{sec}$ & $20 \mathrm{sec}$ & $20 \mathrm{sec}$ & $20 \mathrm{sec}$ \\
Forward Delay & $15 \mathrm{sec}$ & $15 \mathrm{sec}$ & $15 \mathrm{sec}$ & $15 \mathrm{sec}$ & $15 \mathrm{sec}$ \\
Aging Time & 20 & 20 & 20 & 20 & 20 \\
\hline
\end{tabular}

Dari parameter-parameter tersebut, dapat dihitung nilai-nilai:

\section{End-to-end BPDU Propagation Delay}

Nilai ini adalah jumlah waktu yang diperlukan untuk BPDU melewati ujung jaringan yang satu ke ujung lainnya.

End-to-end_BPDU_propa_delay

$=(($ lost_msg +1$) \times$ hello $)+(($ BPDU_Delay x $($ dia -1$))$

$=((3+1) \times$ hello $)+((1 \times($ dia -1$))$

$=4 \mathrm{x}$ hello + dia -1

$=4 \times 2+4$

$=12 \mathrm{sec}$

\section{Message Age Overestimate}

Tujuan dari parameter ini untuk menghitung age BPDU sejak asalnya. Asumsi tiap bridge meningkatkan message age BPDU 1 detik. Formulanya:

Message_age_overestimate

$=($ dia -1$) \times$ overestimate_per_bridge

$=$ dia -1

$=4$

\section{Maximum Frame Lifetime}

Waktu maksimum frame sebelumnya dikirim jaringan bridge tetap di jaringan sebelum frame mencapai tujuan.

Maximum_frame_lifetime

$=$ dia $\mathrm{x}$ transit_delay + med_access_delay

$=$ dia +0.5

$=5.5$

$=6$ (dibulatkan)

\section{Maximum Transmission Halt Delay}

Nilai ini adalah waktu yang diperlukan guna secara efektif mem-block sebuah port, setelah keputusan untuk block dibuat. IEEE menghitung satu detik sebagai maksimum dari event ini.

Formulanya:

Maximum_transmission_halt_delay

$=1$ 


\section{Menentukan Shortest Path ke Root Bridge}

Setelah root bridge ditentukan, setiap switch/bridge akan menentukan cost dari setiap path yang mungkin dari dirinya ke root bridge. Port yang terhubung pada path yang memiliki cost paling kecil disebut root port. Jarak terpendek dari setiap segmen ke root bridge juga ditentukan, sehingga port yang dituju dalam suatu segmen agar diperoleh link cost paling kecil disebut designed port. Port yang tidak didefinisikan akan diblok agar tidak terjadi loop. Port yang diblok ini tetap dapat memperoleh BPDU agar saat terjadi kegagalan dalam suatu path, data dapat melalui port yang diblok sebelumnya.

Di bawah ini merupakan gambar Rangkaian Switch Redundant (Gambar 8).

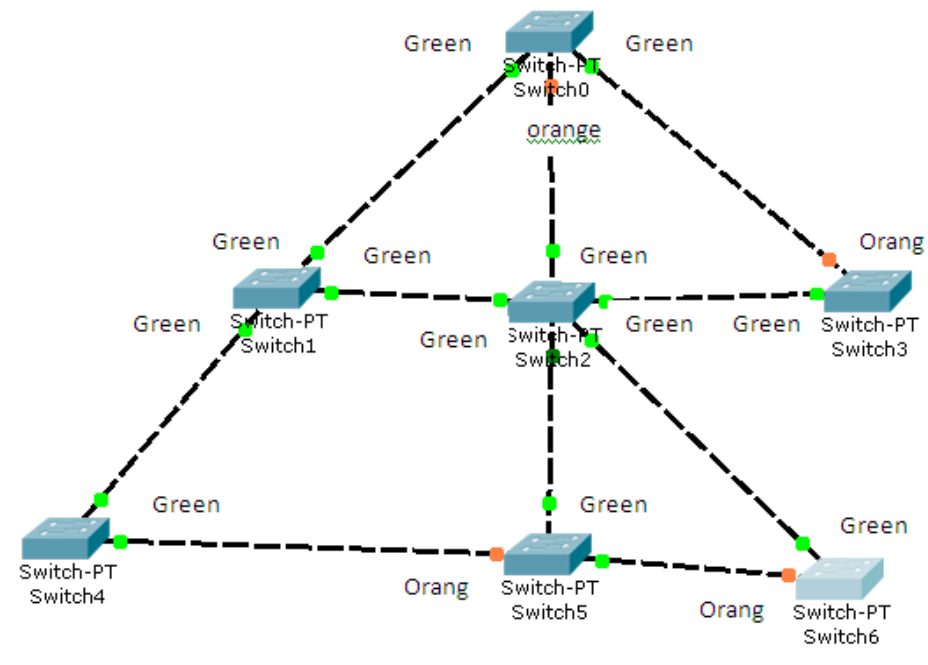

Gambar 8 Rangkaian Switch Redundant

Dari gambar di atas terlihat port yang berbeda warna. Port yang berwana hijau menandakan bahwa port itu aktif (forwarding) sedangkan port yang berwarna oranye tidak aktif (blocking).

Berikut adalah deskripsi spanning tree untuk beberapa switch (Gambar 9 - Gambar 15).

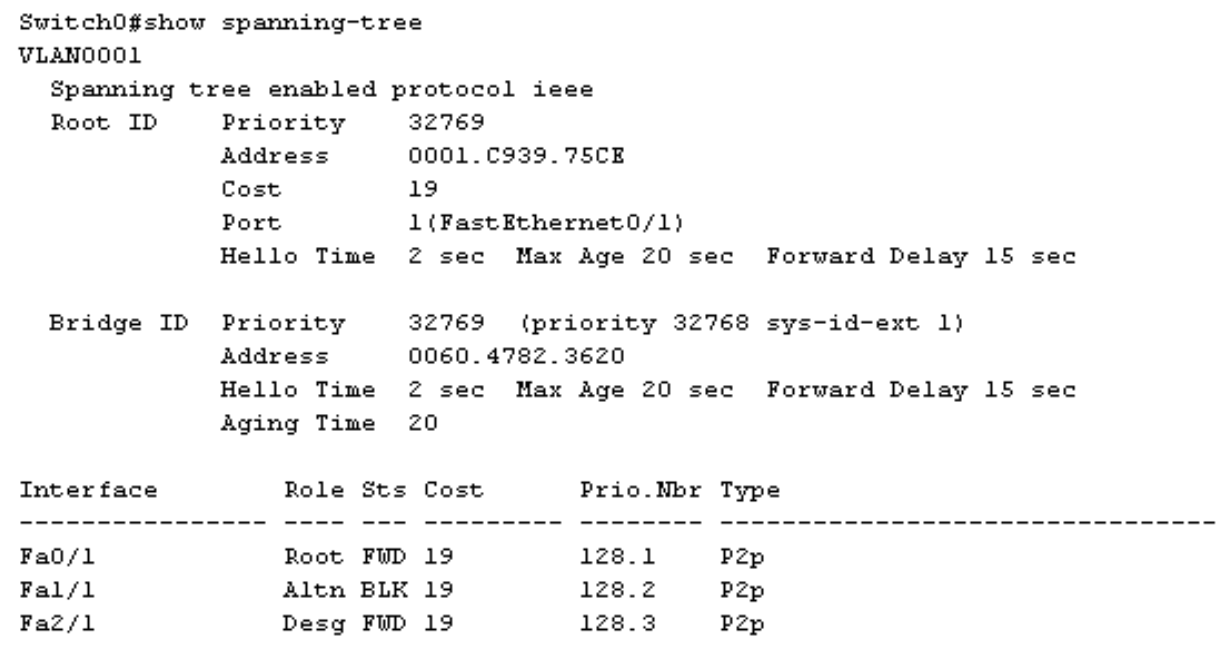

Gambar 9 Deskripsi Spanning tree Switch 0 


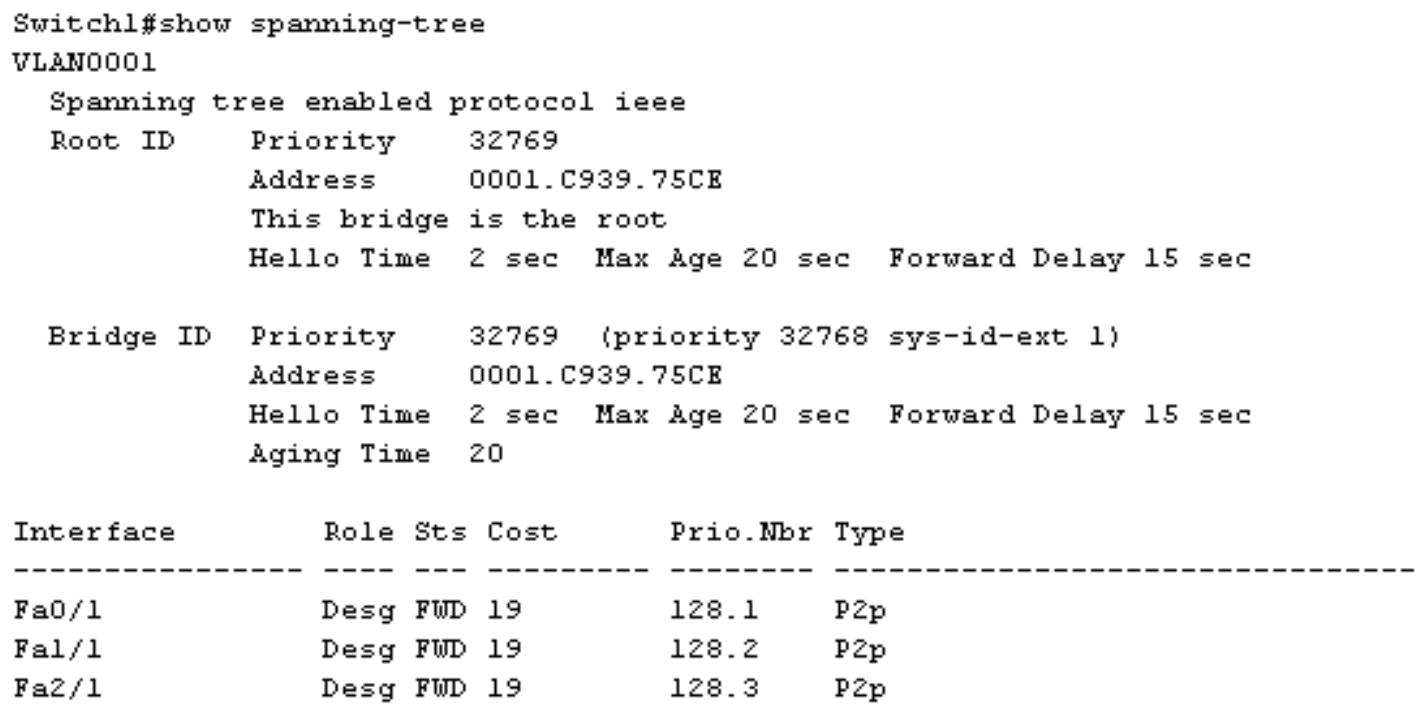

Gambar 10 Deskripsi Spanning tree Switch 1

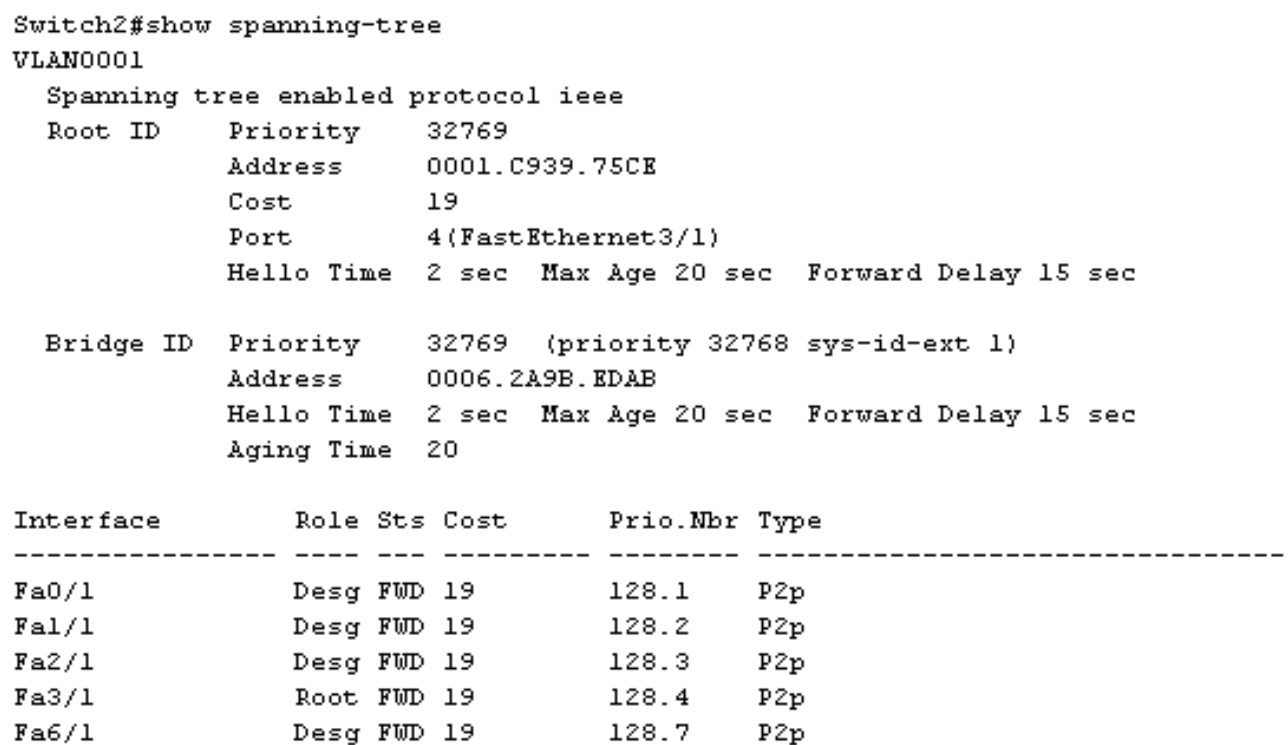

Gambar 11 Deskripsi Spanning tree Switch 2 


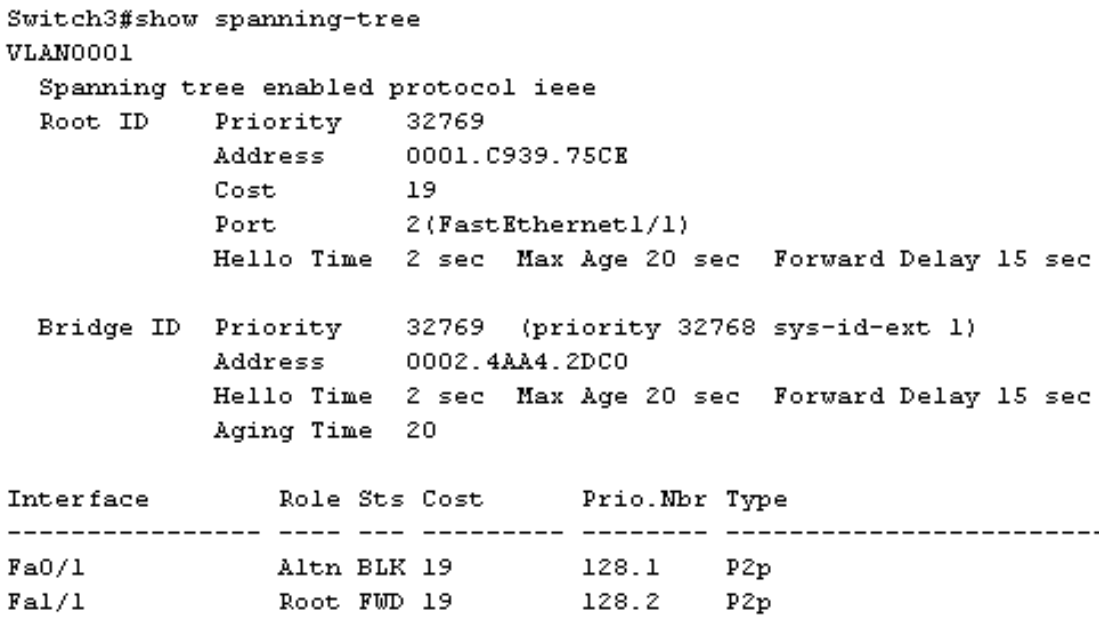

Gambar 12 Deskripsi Spanning tree Switch 3

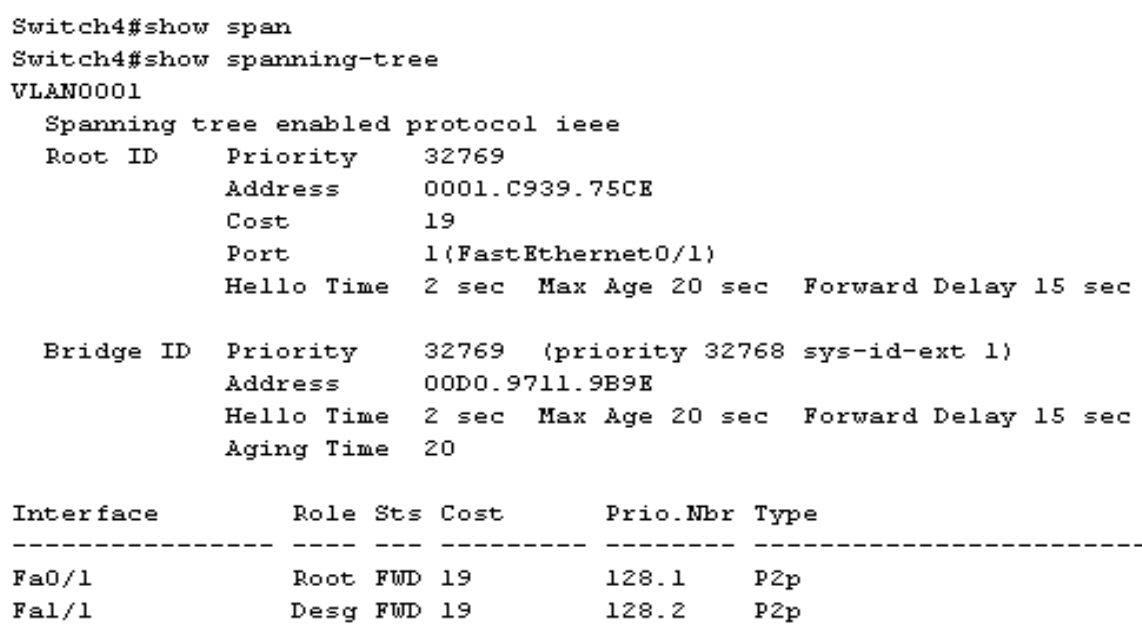

Gambar 13 Deskripsi Spanning tree Switch 4

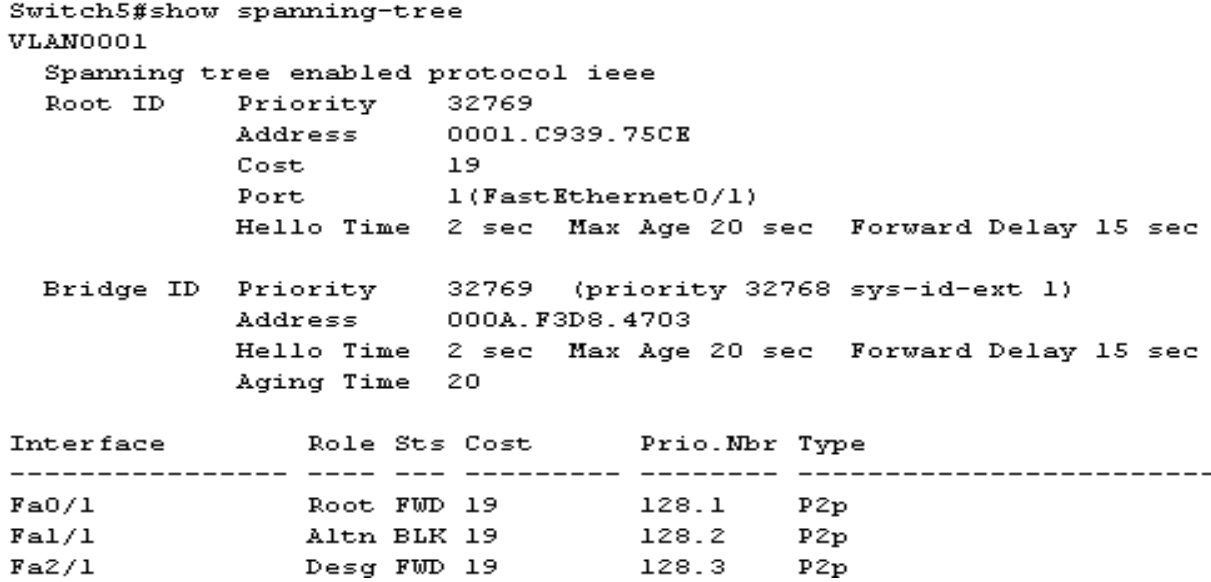

Gambar 14 Deskripsi Spanning tree Switch 5 


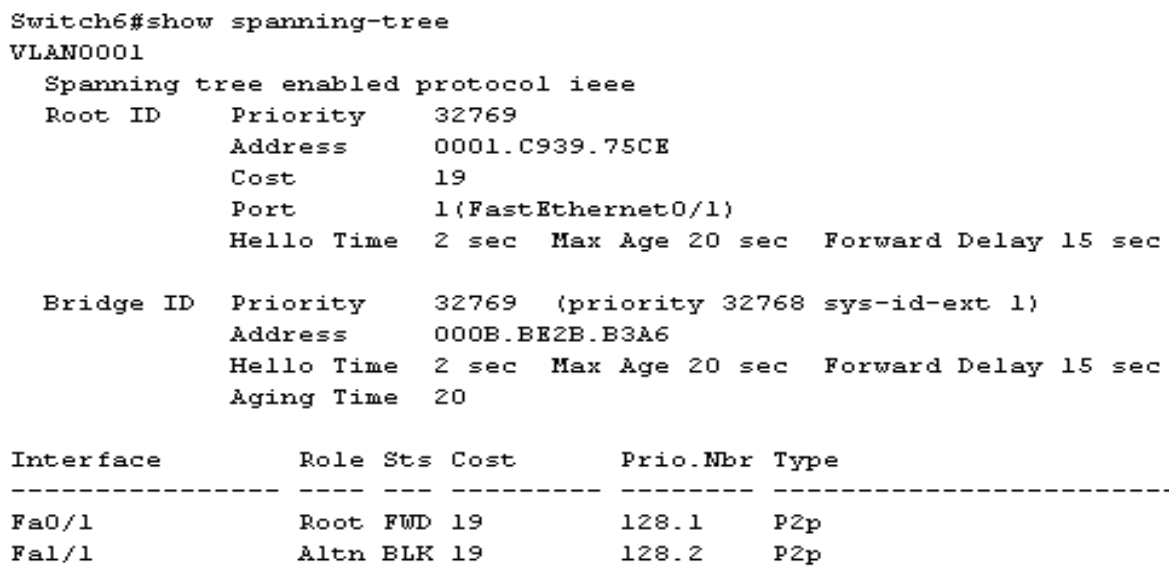

Gambar 15 Deskripsi Spanning tree Switch 6

Deskripsi rangkaian di atas didapat dari kondisi default. Jelas terlihat bahwa Switch 1 menjadi root bridge karena memiliki MAC-Address terkecil. Walaupun topologi di atas menggunakan spanning-tree (tidak ada loop), penempatan root bridge kurang tepat sehingga spanning tree tidak tepat (menurut teori), karena penempatan root bridge yang tepat berada di pusat sehingga jarak ke ujung node sejajar dan mengoptimalkan pengiriman BPDU. perintah:

Dengan mengganti prioriti Switch 2 menjadi lebih kecil dari nilai default menggunakan

Switch2(config)\#spanning-tree vlan 1 priority 4096

Maka Switch2 menjadi root bridge karena default priority id = 32768

Berikut adalah deskripsinya (Gambar 16).

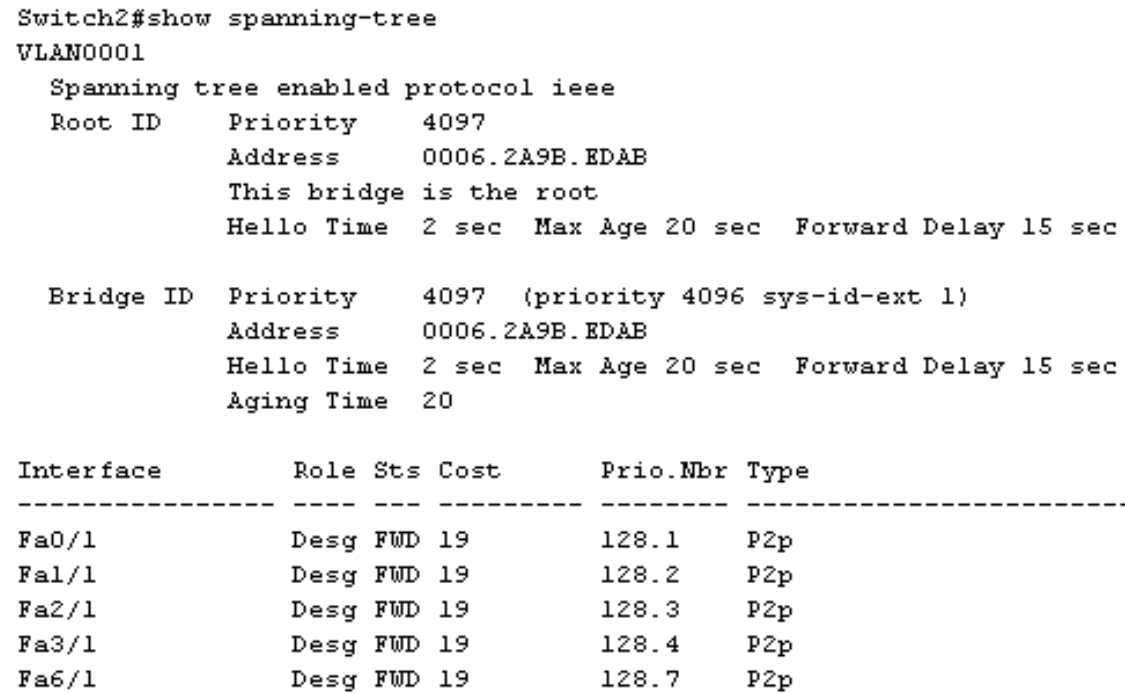

Gambar 16 Deskripsi Spanning tree di Switch2 (menjadi root bridge) 
Konvergensi suatu Spanning tree yang menggunakan standar IEEE 802.1d dapat menghabiskan waktu hingga 50 detik yang didapat dari delay 20 detik saat kondisi blocking, 15 detik dari forward delay Listening dan delay 15 detik dari forward delay Learning.

\section{PENUTUP}

Spanning tree menyediakan redundansi antara bridge atau switch pada jaringan. Semakin banyak switch yang dipakai, penggunaan spanning tree menjadi semakin penting. Dengan Spanning tree Protocol, broadcast storm dapat dicegah sehingga optimasi jaringan menjadi tercapai. Pengunaan Spanning tree juga dapat menyediakan konvergensi panjang yang tidak diharapkan pada kejadian kegagalan jaringan, sehingga untuk mencapai fungsi Spanning tree yang optimal diperlukan pemahaman untuk mendesain topologi jaringan yang baik dan benar dan pengaturan rute Spanning tree berdasarkan path length, weight dan scalability (Keerthana).

\section{DAFTAR PUSTAKA}

Arora S., Garg M.L. (2013). Neighborhood Search for the Bounded Diameter Minimum Spaning Tree. International Journal of Emerging Technology and Advanced Engineering, 3 (2).

Atif, Syed Muhammad. (2011). RRSTP: A spanning tree protocol for obviating count-to-infinity from switched ethernet networks. International Journal of Computer Networks (IJCN), 3 (1).

Keerthana, L., Sampoomam, K.P. (2012). Improved multispanning tree routing using efficient and reliable routing algorithm for irregular networks. International Journal of Electronics and Computer Science Engineering.

Lammle, Todd. (2002). CCNA: Cisco Certified Network Associate Study Guide (3 ${ }^{\text {rd }}$ ed.). Alameda: SYBEX. 